\title{
XXIII. On the behaviour of liquids and gases near their critical temperatures
}

\author{
J.W. Clark
}

To cite this article: J.W. Clark (1880) XXIII. On the behaviour of liquids and gases near their critical temperatures, Philosophical Magazine Series 5, 10:61, 145-155, DOI: 10.1080/14786448008626911

To link to this article: http://dx.doi.org/10.1080/14786448008626911

曲 Published online: 08 May 2009.

Submit your article to this journal $\sqsubset \pi$

Џ Article views: 3

Q View related articles $\asymp$ 
TH E

LONDON, EDINBURGH, AND DUBLIN

\section{PHILOSOPHICAL MAGAZINE}

\section{AND \\ JOURNAL OF SCIENCE.}

[EIFTH SERIES.]

$S E P T E M B E R 1880$.

XXIII. On the Behaviour of Liquids and Gases near their Critical Temperatures. By J. W. CLARK*.

\section{[Plate III.]}

TN 1822 Baron Caignard de la Tour $\dagger$ showed that the effects 1 of heat on a liquid enclosed in a vessel adapted to the purpose, was to convert it into vapour at a volume a little more than twice that which it originally possessed. Within a certain limit he found the temperature at which this change occurred was independent of the ratio existing between the volume of the liquid and that of the tube, but above that limit the conversion was first observed at a higher temperature. Brünner $\ddagger$, after an extensive discussion of previous memoirs, states the results of his observations upon the decrease which heat produced in the height to which water, ether, and olive oil rose in capillary tubes. He experimented at temperatures below $100^{\circ} \mathrm{C}$. In 1857, from Brünner's expression for this decrease in the case of ether, Wolf $\S$ calculated the temperature at which the level of the liquid in the capillary tube should coincide with that outside it; and in the attempt to test his conclusion experimentally he found that it sank below the liquid in the external tube. He stated that the surfaces became convex, and that the depression was the result of true

* Communicated by the Physical Society.

$\dagger$ Ann. de Chim. et de Phys, t. xxi, p. 127 and p. 178; ibid. t. xxii. p. 411.

$\ddagger$ Pogg. Ann. der Phys. u. der Chemie, Bd. lxx. S. 481 .

$\$$ Ann. de Chem. et de Phys. t. xlix. p. 272.

Phil. Mag. S. 5. Vol. 10. No. 61. Sept. 1880. 
capillary action, as in the case of mercury. Drion * then took up the subject, and ultimately came to the conclusion that the depression of the liquid in the capillary tube just before its vaporization was the result of a less rapid expansion produced by a difference of temperature too small to detect with a thermometer. He described the surface of the liquid at the moment of disappearance as perfectly plane, and the apparent convexity as the result of refraction.

Mendelejeff $\dagger$ appears to have misunderstood Wolf; for in 1870 he writes :- "Wolf hat im Jahr 1858 (Ann. de Chim.et de Phys., t. 49, p. 259) gezeigt dass bei der Temperatur bei welcher Aether in zugeschmolzenen Röhren ganz in Dampf verwandelt wird der Meniscus verschwindet und dass Niveau des Aethers in der Capillarröhre und in der weiten Röhre gleich ist. Die Beobachtung wurde von Drion (ibid. 1859, t. 56, p. 221) bestätigt und erweitert." The researches of Dr. Andrews $\ddagger$ are too well known to need special reference here; and the discussion of a paper by Dr. Ramsay $\S$, on the " Critical State of Gases," will be best left until the completion of the work in part described in this paper. Messrs. Hannay and Hogarth $\|$ have recently shown that under certain conditions solids may be dissolved in gases. Unfortunately, $\mathrm{Mr}$. Hannay's paper, "On the Cohesion Limit," recently communicated to the Royal Society, is not yet printed; so that reference to it must be left until a future occasion.

In December $1878 \mathrm{I}$ read a short preliminary note before the Society, "On the Surface Tension of Liquified Gases," in which the results of some measurements on sulphurous anhydride at low temperatures were given $\%$. Last year, at the Society's meeting at the Royal Indian Engineering College in June, a curve showing the height at which sulphurous anhydride stands in a tube at temperatures between $-17^{\circ} \mathrm{C}$. and the critical temperature was shown, and the depression of the liquid in a capillary tube, with some unsuccessful attempts to determine the cause of it, were described. As this is the last meeting of the session, I beg leave to lay the result of the inquiry before the Society. 1859 .

* Ann. de Chim. et de Phys. 1859, p. 221 ; and Comptes Rendus, t. xlviii.

+ Pogg. Ann. 1870, Bd. 141, S. 621.

† Phil. Trans. 1869, p. 575; ibid. 1876, p. 421.

\$ Proc. Roy. Soc. vol. xxx. p. 323.

Ibid. xxix. p. 324 ; ibid. xxx. pp. 178 and 188.

9 I have since found that the value then given is considerably too low, no correction for the diameter of the external tube having been made. To Professor Quincke I am greatly indebted for having directed my attention to the previously reasoned observations of Wolf and Drion here quoted, and for having kindly supplied me with most of the above references. 
Two methods of heating will be noticed in this paper. The first consists merely in heating a large test-tube of oil over a rose gas-burner, the experimental tube being suspended vertically in its axis a little above the bottom by a fine platinum wire. Numerous experiments have been tried with U-tubes of which the branches were of equal diameter and glass-thickness; and the results show that the heating, although rapid, is nearly, if not quite, uniform. It is worth notice, however, that at temperatures very near the critical, the density of liquid and vapour are so nearly equal that when the heating is made unequal, the entire disappearance of the liquid from one branch of the tube does not affect its level in the other. The second method of heating is more complex, but has answered the purpose sufficiently well to deserve brief description. In the middle of a four-litre beaker of oil* is fixed a round-bottomed thin flask of 1.5 litre capacity. The neck, which is about 3 centims. in diameter, is thickly wrapped round with cotton wool and calico, and is long enough to rise 7 centims. above the perforated cover which closes the beaker. The beaker rests on wire gauze carried by a large iron ring, and is surrounded by a tin cylinder 8 centims. wider than the beaker, furnished with two small glass windows on opposite sides, The neck of the flask passes through the cover of this outer case, and is closed air-tight by an indiarubber cork, through which the bulb of a long-stemmed thermometer is inserted. Just below the cork is fused into the neck a narrow glass tube connected with a slightly modified Bunsen regulator (fig. 1, Plate III.) by a short piece of composition pipe (a) 2 millims. in diameter $t$. The other end communicates through a short glass tube $(b)$ with the air-mercury bulb of the usual regulator. A small glass stop-cock (c) serves to place the flask and regulator-bulb in communication with the air. A large rose burner protected from air-currents heats the beaker of oil.

When the apparatus is in use the experimental tube is suspended in the middle of the flask by a thin wire, the glass stop-cock $(c)$ of the regulator.opened, and a small gas-flame lit beneath the beaker. When ether is used in the experiment, in from eight to ten hours the temperature rises to within

* The best salad oil heated out of contact with such metals as copper and iron will bear repeated heating to $200^{\circ} \mathrm{C}$. It ultimately becomes thicker and denser, and exhibits a green fluorescence. By long exposure to the action of air and light, particularly in thin sheets, it regains its transparency and again becomes fit for use. It should be noticed that some sorts of glass are violently attacked by hot oil.

$\uparrow$ These regulators may be obtained from Mr. Bel, 34 Maiden Lane, Strand. 


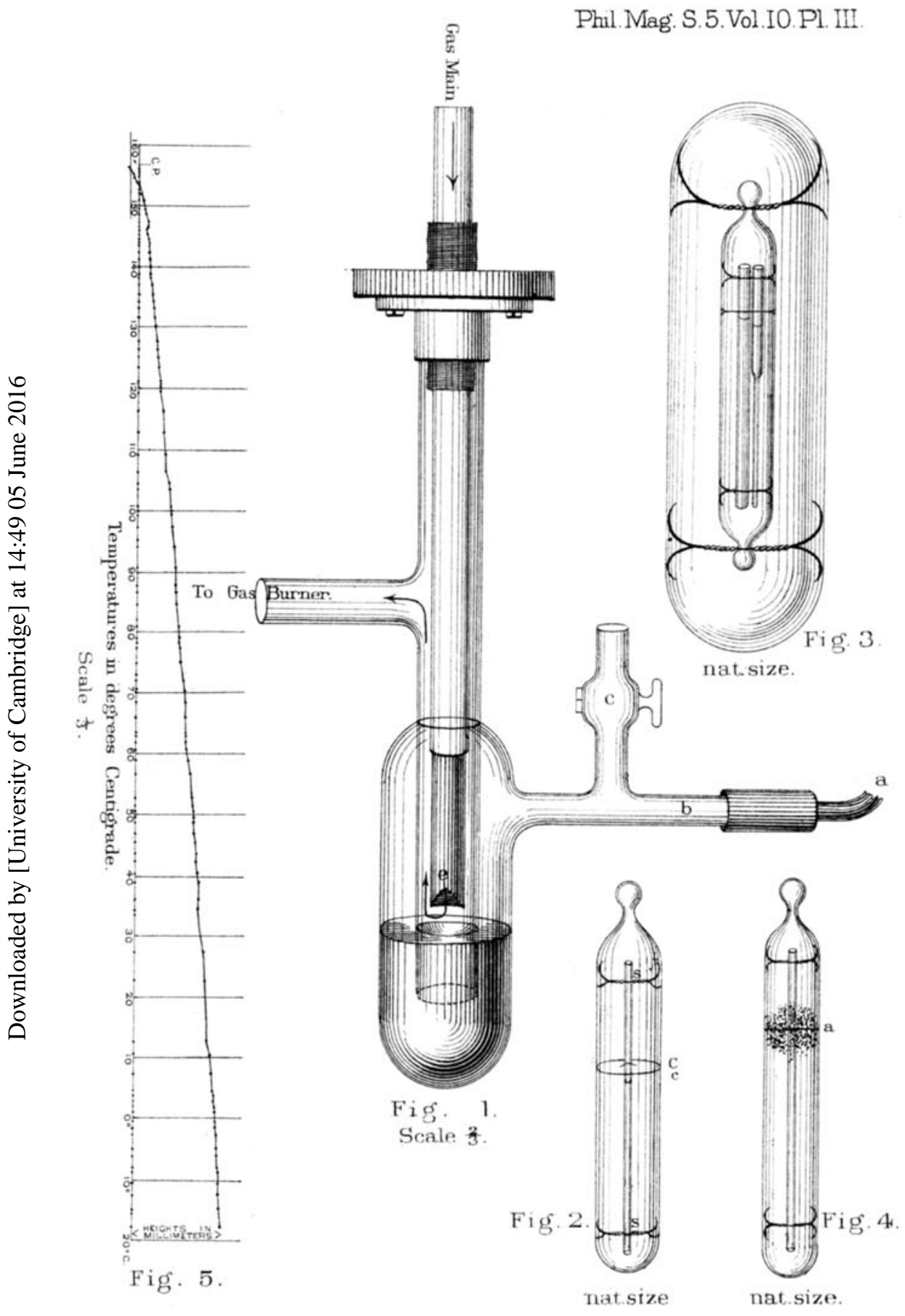


three or four degrees of the critical ; the glass stop-cock $(c)$ is then closed, and the pressure of the expanding air in the flask begins to raise the mercury until it meets the platinum tabe (e) of the regulator, which is previously screwed down till within about 3 millims. of the surface of the mercury. Some two or three hours later the critical temperature is reached. The light from a paraffin lamp passes through a cylindrical lens, and enters through one of the glass windows in the case enclosing the apparatus, thus rendering the experimental tube visible through the other window. The observations are made with a cathetometer-telescope.

Early in this inquiry it was found that so many circumstances influenced the depth to which the liquid was depressed in the capillary tabe, that two different tubes could be satisfactorily compared only when enclosed in the same external tube ; and if the effects of slow and rapid heating are to be compared, the tubes should be of the same thickness of glass. Small springs of thin platinum (S, fig. 2) fix the capillary tubes vertically in the axis of the external tubes, which latter have been employed of various diameters between 2 and 20 millims. When the slow heating-apparatus is used, the experimental tube (enclosing the capillary tube) is fixed in the axis of a tube of considerably greater diameter, which is then exhausted of air and hermetically sealed (see fig. 3). Ether distilled from calcic chloride has been the liquid most frequently employed; but, so far as I am aware, all the results about to be described are also obtained with alcohol, sulphurons anhydride, and carbonic disulphide. Water attacks glass so rapidly that it is difficult to ascertain what is taking place in the tube; but it probably forms no exception to the liquids mentioned.

After the introduction of the capillary, the external tube is filled with liquid, and the air removed as completely as possible by repeated boiling, and the volume of the liquid is reduced to a convenient extent. When such a tube contains ether and is heated, the liquid sinks in the capillary tube and rises in the outer, the expansion becoming more and more rapid as the critical temperature is approached. About $2^{\circ} \mathrm{C}$. below this temperature the meniscus in the capillary tube stands at the same level with that in the external tube. Both surfaces are then distinctly concave. In the case of alcohol the temperature at which this is observed is probably a little more, and for sulphurous anhydride a little less, than $2^{\circ} \mathrm{C}$. below the critical temperature. The exact temperature is affected by a number of circumstances : thus it is lower with a wide capillary tube than a narrow one, and for the same capillary tube it is also lower when this tube is deeply immersed 
in the liquid. Continuing the heating, the meniscus (c) in the capillary is seen below that (C) in the external tube (fig. 4). It then gradually loses its concavity, becomes successively plane and less defined, and frequently presents a more or less convex appearance before finally vanishing. Meanwhile the liquid in the external tube expands and undergoes the same changes, the defined surface appearing more or less convex, - and then becoming black and ill-defined. It first ceases to be visible in the capillary tube. The curve fig. 5 , Plate III., shows the changes in the height of liquid sulphurous anhydride in a capillary tube of 0.4358 millim. diameter in an external tube $3 \cdot 2$ millims. wide. The abscissæ are in degrees centigrade, the ordinates in millimetres. The measurements near the critical temperature could only be made with difficulty, and are consequently less reliable than those made at a lower temperature. Measurements of the depression of the liquid, or even of the diameter of the capillary tube in which the depression is observed, possess but little value, other conditions (e.g. rate of heating, \&c.), incapable of exact expression, exercising too great an influence upon it. When the tube is rapidly cooled a local cloud of very fine particles suddenly makes its appearance, in the middle of which the liquid first appears as a fine horizontal line (fig. 4). In the capillary tube this cloud extends to a considerably greater distance, both upwards and downwards, than in the external tube. Probably this is connected with a surface-action, to be described subsequently. The mean position of the cloud is nearly that at which the tube-contents disappeared on heating. The formation of this cloud reminds one forcibly of the sudden crystallization of a supersaturated solution. The volume which the liquid then first occcupies is less than that which is possessed before its disappearance, and is considerably less if the black ill-defined surface visible on heating be taken into consideration. A persistent tendency on the part of the ether and sulphurous anhydride gases to condense at a lower temperature (particularly when somewhat rapidly cooled) than that at which they were formed is very noticeable*. Rapidly cooled (especially in narrow external tubes) the liquid, when it first becomes visible on condensation, is either level in the capillary and external tubes, or higher in those tubes in which the depression on rapid heating has been the greatest. When

* Although it is premature to draw any definite conclusion from this, it may be of interest to recall the researches of Magnus (Pogg. Ann. xxxviii. 592), and Regnault (Mémoires de l'Académie 1862, xxvi. 715-749, 335664 ) on the vapour-pressures of liquid mixtures, which seem to bear a possible relation to it. In this connexion see also Cailletet's paper (Phil. Mag. March 1880, p. 235). 
slowly cooled, or even when somewhat rapidly cooled in an external tube of large diameter, the liquid condenses in greater quantity in the external tube than in the capillary tube, and hence the liquid has to rise in the capillary tube before it reaches the level of the liquid outside. This is easily seen to be the case from the shape of the condensing cloud in an external tube 20 millims. in diameter. It will be subsequently seen that the resistance which the narrow tube offers to the flow of the liquid through it, is at least very closely connected with the cause of the depression*.

When the tubes are very slowly heated in the apparatus already described, the above phenomena are considerably modified. The volume occupied by the same liquid before its vaporization is then seen to be far greater than that occupied by it when rapidly heated. To illustrate this the volume of ether in a certain tube at the ordinary temperature was roughly 25 . Rapidly heated, the volume at which the liquid disappeared was between 35 and 40 ; and at a volume of about 45 the last traces of black cloud had gone and the contents of the tube appeared perfectly homogeneous. Slowly heated when the liquid had expanded to a volume of 52 , the meniscus was slightly, but perceptibly, concave, and disturbed by a rising bubble of gas. The enclosed capillary tube was not long; and the liquid expanded until it reached the top, and then poured into the tube and filled up the existing depression. Indications that a higher temperature is required for this increased expansion of the liquid have been observed; but whether the temperature at which the liquid disappears is the same for rapid and slow heating has not yet been satisfactorily determined. Continuing to heat, the liquid expands, and the surface is reduced to a thin and often waving line, obliterated by further expansion, or lost amongst the frequent strix. Under these circumstances the volumes of disappearance and reappearance are nearly equal, and the corresponding temperatures sometimes differ by less than $0^{\circ} \cdot 1 \mathrm{C}$. A very slight sudden rise of temperature, when the liquid has expanded beyond the volume at which it disappears under rapid heating, suffices to replace the defined surface by the black ill-defined one before described; but, apparently, when this expansion has proceeded too far, the surface then becomes broad and ill-defined, but not black. It then passes from the liquid through this ill-defined state without expansion; and the liquid in a rather wide capillary tube is then seen to be level with that outside it. Slowly cooled, the tube frequently becomes uniformly filled with striæ,

* For this idea $I \mathrm{am}$ indebted to a suggestion made to me by my riend Mr, Eagles. 
and the light transmitted through the experimental tube by the paraffin lamp before described is observed to become gradually redder and redder. This is succeeded by the formation of a whitish incipient cloud, which finally precipitates in visible particles, often throughout the whole tube. The liquid contracts from the first moment of its condensation until it regains its original volume. Slow and regular cooling seems more difficult to attain than the corresponding conditions on beating.

When the external tube contains rather less ether than the above-that is, when about one third filled, and rapidly heated, the liquid expands and passes into gas in the usual way. Very siowly heated the liquid also expands; but after reaching a certain maximum volume, it very gradually diminishes and evaporates away. If the volume of liquid at its point of maximum expansion happens to be such that the liquid in the external and capillary tubes are almost level, the meniscus in the capillary tube shows a slight tendency to increase its height above the surface when the contraction commences. A slight sudden rise of temperature produces a result similar to that described in the last case. On cooling, the liquid in such a tube undergoes a momentary and almost inappreciable increase of volume just after condensation, and then contracts to its initial volume as in the previously described tubes. If a tube contains still less ether than the last mentioned, the liquid undergoes a more marked increase of volume when it first condenses; and this continues longer before the normal contraction sets in.

Very near the critical temperature the density of liquid and gas are almost equal; and hence it is that the meniscus in the capillary tube may remain depressed for as much as an hour and a half, although very slowly following the upward motion of that in the external tube. The meniscus in the capillary tube usually fades away a little before the surface ceases to be visible in the external tube. This may be due to its being under a slightly lower pressure.

The meniscus in a wide capillary tube is observed below the surface of the liquid in the external tube before that in a capillary of small diameter ; and rapidly heated, the depression usually remains greater in the wide tube until the surface ceases to be visible. This disappearance frequently takes place first in the small, then in the larger capillary, and lastly in the external tube; when the heating is sufficiently slow, the depression becomes greatest in the tube of small diameter. Slow or rapid heating and slow cooling alike show the depression is greater in a tube roughened by hydrofluoric acid than it is in a smooth one of the same size. When the 
heating is rapid, the depression in a capillary tube the immersed half of which has been previously heated and drawn out until the diameter is very small is less than it is in the corresponding tube of uniform diameter throughout. Slow heating reverses this result, as shown in fig. 3. By the mere contraction of the extreme end of the immersed part of a capillary tube the depression is almost uninfluenced. The results above described are not invariable (and some points connected with them are still the subject of inquiry); but under conditions which are apparently the most free from error they become sufficiently so to justify their being regarded as normal.

It seems probable that the effects of unequal and irregular heating are completely removed from the above experiments; for the liquid is equally depressed in two capillary tubes of equal diameter, one made of very thick, and the other of very thin glass. Rapidly heated, the depression reaches a maximum in the thick glass tube. Of two similar capillary tubes the most deeply immersed always shows the deepest depression; but the length of the tube above the liquid is apparently without influence. 'This led to the result described to the Society in June 1879, viz. that when the capillary tube does not dip more than a millimetre or two below the surface the liquid disappears at the same level in the capillary and external tubes.

It has been previously stated that the liquid sometimes appears convex near the critical temperature. With ether in a tube 20 millims. in diameter, this apparent convexity is so well marked that I had at first much difficulty in satisfying myself that such was not the case. By means of a lamp, cylindrical lens, and slit, a bright line of light is easily thrown into the liquid in such a tube heated in a large beaker of oil. The changes in the form of the reflected image were then observed; and from this it was inferred that when the liquid surface appears convex and well-defined, as seen through the horizontal telescope, it is slightly but unmistakably concave, and remains so until it loses the power of reflecting when it is plane. This apparent convexity is caused by the raising of the far edge of the liquid by refraction; or perhaps it may resemble mirage, as I have distinctly seen the surface of the liquid in the horizontal telescope. The surface subsequently becomes black and ill-defined, and, as Professor McLeod has pointed out to me, closely resembles the surface of alcohol and water in a test-tube into which they have been carefully poured so as not to mix. The band of light which leaves the cylindrical lens, and passes through the vertical tube of ether, gives 
rise to some remarkable refraction figures at the* surface of the liquid. By substituting the test-tube of alcohol and water for the tube of ether, corresponding figures are obtainedheat in one case, and diffusion in the other, causing these figures to pass through the same changes. It appears possible that the black surface may be due to the mixing of the liquid ether with its vapour when they are of nearly equal density. This view receives some support from the fact that just before the defined surface of the liquid is lost, the convectioncurrents become so rapid and violent as to disturb and apparently almost break through it into the vapour above.

The above conclusion as to the form of the surface receives confirmation from some experiments with an external tube enclosing two glass plates 0.15 millim. thick, and 11 millims. wide, and separated from each other by a short distance. Not the least rounding of the surface of the liquid could be detected either between or around the plates. That no depression of the liquid was observed between the plates, corresponding to that in the capillary tubes, may be explained by the very small expansion of the liquid in this tube at that point at which the depression usually takes place. Under the sume conditions the depression is absent also from a capillary tube. The expansion, as already stated, is dependent upon the amount of liquid in the tube and upon the rate at which it is heated. On cooling, just as the cloud appeared, and before the liquid line had made its appearance in it, an interesting action was observed taking place on the surfaces of these glass plates; for, extending downwards into the cloud and considerably above its upper limit, a liquid film could be seen running over their surfaces. This probably affords evidence of a surface-action preceptibly influencing the position at which the condensation of the liquid takes place.

It remains only to briefly notice a class of facts to which reference has not yet been made, but which includes certain conditions capable of modifying some of the results described in a part of this paper. It has been very frequently observed that when a tube is heated for the first time, the depression is smaller than it is when the tube is again heated within a short time of the first experimnnt. In a few capillary tubes the liquid is seen to disappear at the same level as the liquid outside them; but reheating shortly after the liquid has condensed, the usual depression is observed. When such a tube has been left a sufficient length of time in contact with the liquid on heating, the same result is obtained as at first; this may be repeated indefinitely. For two tubes this time has been determined, and in both cases found to be about 20 hours; a 


\section{On Liquids and Gases near their Critical Temperatures.}

shorter period merely sufficed to dininish the depression. Probably closely connected with this action is the gradual decrease Quincke* has observed that time produces in the form of a bubble of gas in a liquid, and of a drop of mercury. To this class of facts are also nearly related the decrease in the intensity of Quincke's $\dagger$ electrical diaphragm-currents, and that which $\ddagger$ I have shown to take place in the electromotive force produced when water is forced through capillary tubes. Elster $\S$ has recently extended the observation to a similar variation in the electromotive force set up by liquids flowing over the surfaces of solids. Dorn\| has investigated at some length the cause of this action in the case of tubes, and has shown that it is capable of modification in various ways, some of which appear capable of exercising a corresponding control over the above-described depression of a liquid in a capillary tube at a temperature near the critical.

It is proposed to continue the still incomplete portions of this inquiry in a paper to the Society next session.

In conclusion I beg leave to express my thanks to Professor McLeod, not only for having advised me to extend my observations to higher temperatures than those at first employed, but also for the willingness he has always shown to aid me with valuable suggestions.

\section{Summary of Contents.}

1. When a tube enclosing a capillary tube dipping into alcohol, ether, or sulphurous anhydride is heated, the liquid sinks in the capillary, and rises by expansion in the outer tube. Between $2^{\circ}$ and $3^{\circ} \mathrm{C}$. below the critical temperatures of these liquids both surfaces become level; and on continuing to heat, the concave meniscus in the capillary tube is seen below that in the external tube. The extent of this depression depends on the diameter \&c. of the capillary tube, and on the nature of its internal surface. When the end of a capillary tube dips very slightly below the surface of the liquid, it is level in the capillary and external tubes at the disappearance of the liquid.

2. In some capillary tubes the liquid is not depressed, but disappears at the level of the liquid in which they are immersed on first heating. Once heated, long contact between liquid and tube is necessary to prevent the formation of the depression

* Pogg. Ann. Bd. clx. S. 576.

$\dagger$ Ibid. Bd. cx. S. 56 .

I Ibid. 1877 , S. 345 .

\$ Inaugural-Dissertation über die in freien Wasserstrahlen auftretenden electromotorischen Krä̈fte. Leipzig, 1879.

II Wiedemann's Ann. Bd. ix. 1880, S. 523. Compare also Helmholtz, Wied, Ann. vii. p. 337 (1879). 
on again heating. For two tubes which were examined, this time was in each case about 20 hours; a shorter period merely sufficed to diminish the depresion. The depression is the result of an action between the liquid and the inner glass surface of the capillary tube.

3 . Indications that surfaces exercise a slight action in determining the position at which the liquid condenses in the external tube have been observed.

4. By reflecting a bright line of light from the apparently convex and well-defined surface of ether in a tube of 20 millims. diameter at a temperature near the critical, it may be inferred to remain concave until it loses the power of reflecting when it is plane. The apparent convexity is the result of refraction, or, perhaps, of an action resembling mirage.

5. The black ill-defined band which immediately succeeds the disappearance of the liquid surface is the result of too rapid heating, and possibly due to the mixing of liquid and vapour when they are of nearly equal density. When very slowly heated, as described, the defined concave surface is gradually obliterated, and is last seen as a fine and often waving line. Under this condition also the volume of the liquid at its disappearance is greater than when it is rapidly heated. When the liquid is vaporized by rapid heating, it has a higher temperature and larger volume at the time of disappearance than it has when first condensed by cooling; slowly heated and cooled, these volumes and temperatures are more nearly the same.

Royal Indian Engineering College, June 1880 .

\section{Vibrations of a Columnar Vortex. By Sir William Thomson*.}

TTHIS is a case of fluid-motion, in which the stream-lines 1 are approximately circles, with their centres in one line (the axis of the vortex) and the velocities approximately constant, and approximately equal at equal distances from the axis. As a preliminary to treating it, it is convenient to express the equations of motion of a homogeneous incompressible inviscid fluid (the description of fluid to which the present investigation is confined) in terms of "columnar coordinates," $r, \theta, z$ - that is, coordinates such that $r \cos \theta=x, r \sin \theta=y$.

If we call the density unity, and if we denote by $\dot{x}, \dot{y}, \dot{z}$ the velocity-components of the fluid particle which at time $t$ is

* From the Proceedings of the Royal Society of Edinburgh, March I, 1880 . 